\title{
As condicións de xénero no contexto migratorio galego ás Américas. Apuntamentos do caso mexicano (1880-1936)
}

\author{
Gender conditions in the Galician migratory context to the Americas. \\ Notes on the Mexican case (1880-1930) \\ DAVID MIGUEL RODRÍGUEZ MARTÍNEZ \\ Universidade de Santiago de Compostela \\ https://orcid.org/0000-0001-5270-3961 \\ miguel.rodriguez@mazarelos.gal
}

\begin{abstract}
RESUMO
A vía da emigración foi unha realidade moi presente na sociedade galega masculina. Non podemos dicir o mesmo das mulleres, que tiveron que afrontar as condicións de xénero tanto na súa partida de Galicia como na súa aventura das Américas. Neste artigo tentaremos achegar algunhas das limitacións que a migración feminina sufriu, centrándonos nos obstáculos socioculturais e laborais nunha sociedade á deriva que invisibilizou ás que se aventuraron a cruzar o Atlántico. Finalmente, aterraremos no caso mexicano e a súas particularidades.
\end{abstract}

Palabras chave: muller, Galicia, movementos migratorios, limitacións, desigualdade.

\section{Abstract}

The way of emigration was a very present reality in Galician male society. The same cannot be said of women, who were victims of the conditions of gender in their departure of Galicia and in their adventure into the Americas. In this article, we will try to approach some of the limitations that women migration offered, focus on factors such as socio-cultural and labor goals in a drifting society that made invisible who adventured to cross the Atlantic. Finally, we will land on the particularities of Mexican case.

Keywords: woman, Galicia, migration moves, limitations, unequality.

No perdí el origen pero sí el lugar, la silla. Me costaría mucho volver a ocupar mi lugar y otra vez, otro dolor, ;no! (Iglesias López, 2006, p.179)

Malia aos notorios avances dende a década de 1980 até a actualidade en canto o estudo da muller nos movementos migratorios ás Américas, a disciplina histórica non centrou a súa axenda principal nas particularidades destes desprazamentos (Cagiao Vila, 
2009). Porén, na memoria de cada familia galega houbo casos dunha tía, filla ou sobriña que probou sorte partindo ben por iniciativa propia ou ben ao ser reclamada por algún familiar. Repasando prensa de época, informes oficiais e testemuñas, pódese construír un relato no que analizar as principais limitacións e condicións de xénero da viaxes de todas elas a finais do século XIX e comezos do XX.

\section{1. «EN GALICIA NON SE PIDE NADA. EMÍGRASE»}

A migración foi un fenómeno propio da Galicia contemporánea que acadou rexistros á altura dos grandes desprazamentos europeos como os irlandeses cara as Américas. No século XIX o país destacaba por un carácter endóxeno, vertebrado por un eixo rural moi vencellado á transformación dos elementos do medio que o rodea (Fernández Prieto, 2000). A crise finisecular supuxo un parteaugas entre o mantemento e a adaptación da sociedade fronte á posibilidade migratoria, e a mobilidade masculina converteuse nunha estratexia fundamental para aliviar a presión da poboación sobre os recursos.

Jose C. Moya sinalou cinco revolucións globais para comprender a etapa finisecular na que o proceso migratorio se enmarcou (2004, p. 57). A primeira foi a revolución industrial, motor do modelo capitalista e da formulación sistemática como prototipo progresivamente global. Estableceuse unha nova orde social moi vencellada ao ámbito económico, onde as mulleres seguiron sufrindo dunha terrible desigualdade salarial e dunhas condicións vexatorias (Rial García, 2009, pp: 77-82). No caso galego, esta revolución industrial estivo dirixida cara a redución dos custos de produción por medio dunha sucesión de pequenas melloras técnicas e tecnolóxicas, sempre tendo presente o seu modelo histórico da pequena explotación agraria familiar (Fernández Prieto, 2000, p. 242).

A segunda revolución foi a dos transportes. A entrada do barco de vapor relevou a concepción dun mundo inabarcable e supeditado ás condicións atmosféricas para comezar a ser unha realidade práctica. Até entón as viaxes a vela duraban case tres meses entre o territorio peninsular e o americano. Coa chegada desta tecnoloxía, levábanse a cabo en tan só unha quincena de días baixo a organización das compañías de transporte e os seus grandes transatlánticos. Unha auténtica válvula de escape do territorio apareceu no abano de posibilidades das familias galegas, provocando a expansión en cantidade e calidade dos desprazamentos. A emigración galega partiu ao novo continente e enviou de volta capitais empregados na mellora de infraestruturas -escolas, vivendas...-, innovacións técnicas e incluso achegas culturais tanto para o cambio tecnolóxico como para a articulación social do agrarismo (Seixas Seoane, 2002).

A terceira tratouse da revolución liberal, símbolo de transición da época moderna e a contemporánea en canto á materia albergante as novas realidades ideopolíticas aínda moi mermadas para as mulleres. Por último cómpre destacar a agrícola e a demográfica, moi relacionadas entre si. O modelo familiar «tradicional» situaba á muller ao cargo da unidade familiar, centrándose no seu desenvolvemento por riba da agrícola onde as 
maquinarias adquiren o protagonismo. Tal e como sinala Villares Paz, a agricultura galega entre 1870 e 1930 foi precisamente unha época de grandes transformacións, estando moi presentes un cambio de réxime de propiedade, unhas condicións técnicas novidosas, e unha primeira modernización agrícola tras un período de estabilidade -que non estancamento- no seu sistema (1985, pp: 95-117).

O problema resultaba nas familias cun modelo superpoboado, que non permitiu o seu mantemento baseado no pequeno minifundismo galego de subsidencia.

\section{OS FACTORES DE ATRACCIÓN DAS NOVAS NACIÓNS LATINOAMERICANAS}

O fluxo migratorio galego supuxo o a creación dunha extensa rede entre os emigrados no lugar de destino e o territorio galego. Esta «emigración en masa» viuse reflectida polo Instituto Geográfico de Estadística, que rexistrou entre 1882 e 1936 arredor de 3.5 millóns de emigrados españois cara as Américas (Sánchez Albornoz, 1995). Secasí, é tal a incerteza en canto á cantidade real de emigrados e retornados, que resulta imposible barallar cifras máis que aproximadas (López Montero, 1983, p. 95). Canarios e galegos encabezaron as listas de emigrantes nestas datas a América, adquirindo unha importancia salientable dende o século XVIII. Os territorios rexistrados como atractivo migratorio dende a realidade española foron Arxentina, Cuba, Brasil e Uruguai, destacando especialmente o primeiro sinalado converténdose Bos Aires na capital da Galicia ultramarina (Sarmiento da Silva, 2006).

Comezando pola vía da Prata, a Pampa é unha das zonas agrogandeiras máis frutíferas do planeta (Ortuño, 2010, p. 36). Sabedores da necesidade dunha man de obra barata, o programa liberal da República arxentina deseñou unha planificación baseada no «gobernar es poblar» de Juan Bautista Alberdi. Após da apertura das súas fronteiras milleiros de barcos cheos de galegos arribaron nas costas rioplatenses co inesperado asentamento no entorno urbano en lugar do rural interior. A fin de contas, se os galegos quixeran continuar nun entorno rural, ben podían quedar no país en lugar de especular cun contexto moi similar. Esas primeiras familias instaladas e afincadas en Bos Aires serviron de ponte e nexo coas futuras remesas de emigrantes galegos, chegando á construción no imaxinario popular dos arxentinos do concepto gallego a calquera inmigrante de orixe peninsular pola súa abundancia (Núñez Seixas, 2002).

Outro caso senlleiro foi o de Cuba. Aínda colonia española, no ano 1880 aprobouse a abolición da escravitude na illa. Por este motivo demandaba unha man de obra e unha inserción en diferentes actividades como a zafra. Ademais disto, as primeiras sospeitas revolucionarias invitaban a ter posibles efectivos que defendesen a posición española sobre a illa, promovendo un gran fluxo dende os portos galegos, conservándose este movemento incluso despois da independencia da illa. Entre 1912 e 1918, o 80\% dos emigrados saídos dende o porto da Coruña emigrou cara Cuba (Campos Álvarez, 1993, p. 137). Os 
motivos foron varios, mais neste contexto un dos principais pretextos foi a fuxida da mocidade destinada ás guerras marroquís. Optaron pola Habana debido á inxente cantidade de veciños, familiares ou coñecidos que os reclamaban para os seus oficios. Estes foron duramente explotados durante os primeiros anos e, nalgúns casos, lograron proliferar e abrir o seu propio comercio para enviar os excedentes ás familias que quedaran no país (Vázquez González, 1988).

Por último está o caso do Brasil. A abolición da escravitude (1888) demandaba braços pra o café, destacando a migración galaica dende portos galegos e portugueses próxima ao medio millón de individuos (Cagiao Vila, 1992, p. 89). Ademais deste oficio, os galegos afincados no Brasil posuíron a meirande parte dos abarrotes ou tendas de secos e molhados, así como as populares panaderías ou pequenas casas de xantar. Destacou como destino Salvador de Bahía, lugar onde estableceron ultramarinos grazas ás cadeas de paisanaxe e aos sistemas de recruta nas parroquias galegas, especialmente da área de Pontecandelas (Samuelle Lamela, 2000, p. 91).

Abarrotes, negocios, traballo no campo... oficios que demandaban unha mocidade masculina pouco - ou nada- especializada. De aí a licenza de Rosalía de Castro para designar a todas esas mulleres que quedaron na Galiza como «viúvas de vivos e mortos», quenes tiveron que facerse cargo da unidade familiar e da administración no país. Así e todo houbo moitos casos nos que, pese á dominación do éxodo masculino, foron mulleres as protagonistas do movemento migratorio cara as Américas.

\section{GALEGAS NA DIÁSPORA: UN CAMIÑO CHEO DE OBSTÁCULOS}

A supeditación das mulleres tanto no ámbito social coma no legal ante os varóns -pais, maridos ou titores- condicionou a liberdade de acción das galegas enormemente, quedando reflectido no desequilibrado balance dos desprazamentos migratorios. As galegas tiveron que enfrontarse a unha condicionante tripla: ser inmigrantes, ser galegas e ser mulleres. Primeiramente o feito de ser inmigrantes nun país estranxeiro dificultaba o seu acceso e a súa inclusión na nova sociedade que as discriminaba no eido socioeconómico ante as mulleres e homes oriúndos en México. Despois temos o feito de seren mulleres, o que provocaba que quedasen excluídas do poder político, económico ou social ao estar reservado este escalafón para os homes (Hernández Borge, 2001, p. 93). Por último ser galegas, cargadas de prexuízos que esta orixe implicaba no imaxinario americano. Un teito de cristal que amosou as dificultades condicionadas polo xénero nas nacións americanas, dende a ollada máis popular até inscrito nas propias leis e marcos xurídicos de época.

Os destinos principais foron os mesmos que os do éxodo masculino, xa que nos casos frutíferos houbo ocasións nas que o home reclamaba o traslado definitivo da súa familia cara o territorio americano. É máis, existe unha relación directa entre as leis de re-agrupación familiar do ano 1921 e a participación delas nestes desprazamentos, coa proliferación cuantitativa segundo nos achegamos á década de 1930. Estas leis permitían 
aos españois que obtivesen a nacionalidade ou tivesen residencia no país de destino reclamar ás súas mulleres e fillos sen ningunha restrición (Ortiz, 2016, p.111). Se nos detemos na prensa de época [fig. 1] vemos como outrora sinalaban o importante incremento de mulleres nos desprazamentos ás Américas.

Neste xornal apréciase unha comparativa entre as diferentes asociacións de auxilio de mulleres emigradas a América e a inacción do caso galego. Se en Francia teñen a Societé d'Emigration des femmes e en Inglaterra a Women's emigration Society, segundo Javier Vales Faílde ${ }^{1}$ as encargadas de auxilio de galegas son as congregacións relixiosas. Apuntou tamén que, entre 1891 e 1898, o Instituto Geográfico Estadístico rexistrou 14.314 mulleres galegas emigradas, ofrecendo xa neste tempo unha cifra senlleira e probablemente pouco representativa da realidade debido á non contabilización dos desprazamentos sen aparición nos rexistros oficiais de carácter clandestino. Estas últimas apareceron reflectidas constantemente na prensa de época debido á súa frecuencia. Un exemplo atópase no Diario de Pontevedra do ano 1900, no que se sinala que «[...] se provee a las mujeres de documentación falsa y se les enseña las contestaciones que les deben dar a los empleados de

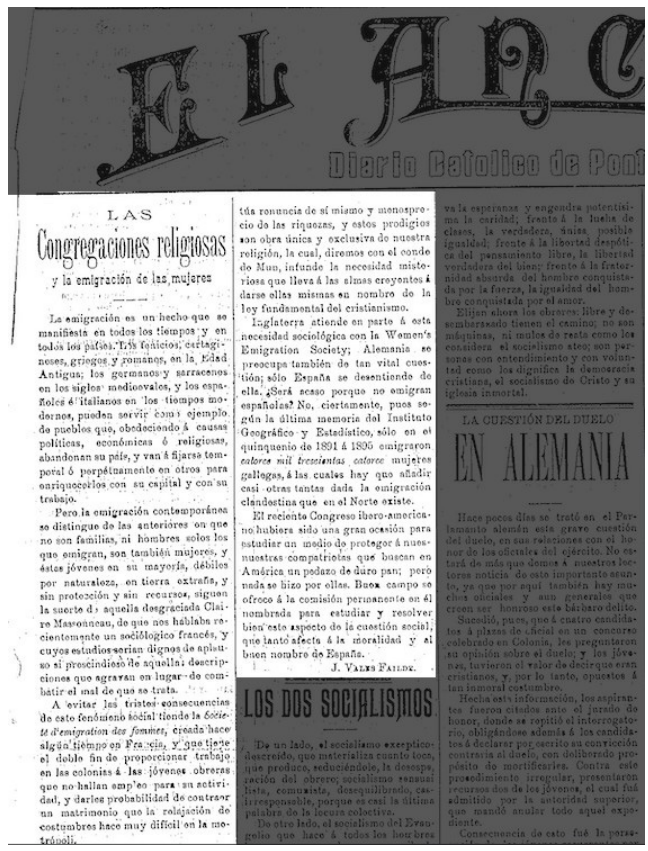

Figura 1. Nova sobre a emigración feminina. Diario Católico de Pontevedra (1048), 04-02-1901. la oficina de inmigración» (Diario de Pontevedra, 1900, p. 1).

Apoiándonos na Estadística de la emigración e inmigración de España para os período 1915-1935 e nas Estadísticas de emigración de 1916 até 1935, houbo un total de 168.452 mulleres emigradas 2 . Se no lustro de 1890-1894 a porcentaxe feminina apenas representaba un 13,18\%, múdase cara un excelso incremento no lustro 1930-1934 onde

1 Nado en Rodeiro en 1872, Francisco Vales Failde foi Xuíz Auditor do Tribunal Supremo da Rota.

2 Pese á exactitude dos datos, faltan os rexistros dos anos 1922 e 1923. Apréciase malia isto o número total de emigradas rexistradas por ano e a súa representatividade coa emigración masculina expresada en porcentaxe. No período 1887-1898 houbo un total de 35.893 emigradas e no correspondente aos anos comprendidos entre 1916 e 1935 houbo un total de 132.559. Para coñecer os datos exacto por ano, véxase Hernández Borge, 2015, p. 230. 
catro de cada dez migracións foron protagonizadas por mulleres galegas (Hernández Borge, 2015, p. 230). Estes datos correspóndense coas leis de reagrupación recén mencionadas e cunha vaga migratoria posterior que atopou un tecido migratorio galego sustentado nos países de destino. No diario El Compostelano, matizando a diferenciación segundo os países de destino, apuntaron que:

La emigración a la Argentina sigue conservando su antiguo carácter de colonización, lo que demuestra por la proporción de mujeres que a ese país emigran -el 60 por 100 de la cifra total- mientras que á Cuba sólo fué un 15 por 100 y á los Estados Unidos un 9 por 100. Esto significa que las familias de los emigrantes á Cuba y Norteamérica quedan en su mayoría en España, lo contrario de las que salen para la Argentina ( $E l$ Compostelano, 1921, p. 3).

Por un lado, vimos o paulatino incremento de mulleres protagonistas do episodio migratorio galego no contexto suxeito a estudo. Por outro, denuncias e protestas ante un abandono nos lugares de destino. Que obstáculos e limitacións atenderon principalmente as galegas nas nación latinoamericanas? Principalmente tres: a dureza da viaxe, a ameaza da prostitución e a desigualdade de oportunidades laborais.

As condicións da viaxe ás Américas foron fortemente criticadas tanto polos propios afectados como polos inspectores e a prensa (Castro, 1999, p. 19). Un millar de pasaxeiros ocupaban unhas atestadas terceiras clases en cada viaxe ás que chegaban grazas ao traballo dos ganchos ${ }^{3}$. Aqueles que prometeron unha rebaixa na pasaxe, un trato de favor ou un auxilio na súa chegada resultaron ser en moitas ocasións membros dunha rede de trata de brancas. É máis, como sinala Cagiao Vila, tamén resultaba perigosa a viaxe ante a ameaza de acoso e abusos por parte da tripulación mariñeira dos grandes transoceánicos «de dubidosa moralidade» (2003, p. 80). Esta serie de feitos foron denunciados na prensa pola forte presencia nos portos galegos. Na portada do diario Áncora de outubro de 1903 xa avisaron que «en los vapores que zarpan de aquel puerto [Vigo] para América embarcan estos días muchas criadas de servir [...] No será extraño que esta corriente de emigración resulte un disfraz de la trata de blancas» (El Correo de Galicia, 1903, p. 2).

Cómpre sinalar a situación da trata na década de 1920. A Sociedade das Nacións declarou como necesaria a intervención inmediata neste eido, coa premisa de formular unha cooperación internacional para o seu paliamento. No diario El Compostelano, F. Yartza recolleu algunhas das notas do acto nas que apareceron referencias que reforzan a perigosidade destas viaxes:

La Comisión técnica, encargada por la Sociedad de las Naciones de informar sobre el estado internacional de este abominable comercio y proponer a las naciones las medidas que puedan adoptarse para extirparlo, ha publicado la primera parte de su

3 Os ganchos eran axentes encargados de percorrer o territorio galego na busca de novos emigrantes aos que lles prometían todo tipo de facilidades para embarcar, tanto legais como ilegais. 
informe, de la cual quiero extraer hoy dos o tres notas interesantes. La primera es que hay convictos y confesos, más de ¡5.000 agentes! Que trafican en este negocio infame. Solamente uno de estos había recibido un encargo para tres años, del que estaba obtener un beneficio líquido de 300.000 pesetas! (El Compostelano, 1927, p. 1)

Esta serie de condenas foron denunciadas dende as Américas debido aos diversos toques de atención emitidos polas nacións do vello continente. O presidente da República Arxentina denunciou fortemente estas malas prácticas, o que apareceu recollido na propia prensa galega. No El Compostelano [figura 2], días despois da conferencia celebrada pola Sociedade de Nacións na cidade de Xénova no ano 1927, apareceu a intervención do presidente Alvear sobre a persecución traducida nun centenar de detencións ligadas á trata internacional de brancas.

\section{La trata de blanoas en la Argentina}

En vista de las revelaciones he. chas recientemente en Ginebra, el presidente de la República Sr. Alvear ha dado 6rdenes para que se esta. blezca en todos los puertos de la Argentina la más severa vigilancias para impedir la trata de blancas.

La Polioía ha practicado estos días un centenar de detenciodes relasio. nadas con el mismo asu jto.

Figura 2. La trata de blancas en la Argentina. Diario El Compostelano, $\mathrm{n}^{\circ}$ 2178, 23-06-1927, p. 2.

Non só houbo denuncias por parte da prensa e dos órganos oficiais estatais. Do mesmo xeito que a relación veciñal nos concellos do país permitiu dar a coñecer a vía da migración mediante experiencias próximas, tamén existiron avisos das problemáticas xurdidas tanto nos casos retornados como nos establecidos na migración. Por unha banda formouse no ano 1923 un Comité Pro-Galicia para denunciar este tipo de cuestións. Incluso circularon entre as vilas galegas os abusos sufridos contra as mulleres nos barracóns de Triscornia na cidade da Habana, advertindo da perigosidade das viaxes (Naranjo Orovio, 1988).

Dende as Américas tamén quedou rexistro nas colectividades galegas emigradas sobre este fenómeno no Boletín Oficial del Centro Gallego. No ano 1926, Ernesto Crespo escribiu un monográfico sobre a situación da trata de brancas que chegan dende portos galegos a Bos Aires. Nel, coméntanse algunhas problemáticas e vicisitudes da cuestión das tratas, apuntando unha escasa intervención tanto dos países de acollida como dos de destino:

Un prestigioso diario matutino, en un editorial que publicó hace un tiempo, decía haber consultado a varios magistrados las causas que hacían ineficaces las disposiciones legales, y recogió de labios de dichos magistrados la opinión de que la policía no combatía con el debido celo esta lacra social, por indolencia o por motivos de otro orden; lo que hacía muy difícil, por no imposible, que un caso de esta naturaleza llegara a los tribunales (Boletín Oficial del Centro Gallego de la Avellaneda, 1926, p. 5). 
Unha vez superados os obstáculos da viaxe chegaron as dificultades na inserción laboral nos países de destino. As galegas cambiaron o rural polo urbano, tendo un novo abano de oficios nos que se empregar pero moitas outras atribucións tradicionais transversais a ambos mundos como a administración familiar e o traballo doméstico. As inmigrantes rivalizaron coas nacionais en oficios vencellados ao desenvolvemento industrial por mor do crecemento urbano deste tempo e a súa demanda de man de obra feminina (Cagiao Vila, 1999, p. 79). Tamén desempeñaron oficios dun nivel de escasa especialización como lavandeiras, cociñeiras e costureiras. Malia isto, houbo un ámbito no que dominou a súa presencia: o servizo doméstico. Ben é certo que as galegas gozaban dunha fama de mulleres traballadoras e moi apreciadas neste eido laboral, mais non debe levar a equívocos. Que fosen cumpridoras cos seus labores e obrigas no traballo non significou que tivesen unha condicións dignas e que fosen recompensadas polos propietarios das vivendas. Elas traballaban durante unha quincena de días sen parar, correspondéndolle dous domingos ao mes de descanso. Esa honradez e fidelidade non era máis que un pretexto de confianza, que permitía explotar ás traballadoras sabendo que cumprirían o seu cometido.

Existiron outros casos nos que arribaban cun respaldo familiar e axudaban nas empresas familiares repartidas nos barrios que adoitaban reunir a un importante contixente dos galegos emigrados nas principais cidades das Américas. Este oficio foi moi pouco recoñecido tanto pola historiografía como no propio contexto suxeito a estudo, xa que se adoita reducir ao seu papel doméstico fomentando o seu subrexistro. Na realidade, aparecen testemuñas de galegas desempeñando incluso traballos atribuídos aos homes como foi o de peón de albanel ou o traballo en factorías, sempre condicionadas polos baixos prezos e as duras condicións de traballo (Samuelle Lamela, 2001, p. 173). Foi frecuente que abandonasen este tipo de labores ao casarse, centrándose na administración da economía familiar e tamén na participación dos pequenos negocios rexentados polo seu marido.

Por último, sinalar a restritiva e discriminatoria lexislación contra a migración feminina tanto no país de partida como nos de destino. Na Real Orde do 7 de outubro de 1902 estableceuse a obriga dunha autorización paterna nas mulleres menores de 23 anos emigrantes, así como un permiso de boas maneiras expedido polo goberno provincial e outro do marido, en caso de ter contraído matrimonio. Por outra banda, existiron constantes medidas para limitar a entrada de efectivos migratorios nos países de destino, que veremos nas seguintes páxinas centrándonos nun casos esquecido pola historiografía debido á súa anomalía: México.

\section{GALEGAS NA REPÚBLICA MEXICANA: UN SELECTO GRUPO}

Dende comezos do século XIX México apostou por unha política de colonización encamiñada á atracción de poboación europea cunha serie de condicións que foron adaptándose ás diferentes situacións do país. Existiu unha gran diferenza entre o México 
pouco frecuentado pola migración galega (1880-1936) e o país coa maior acollida do exilio republicano após do alzamento fascista (1936-1939). Malia que houbo un incremento durante o proceso de estabilidade do porfiriato, os datos sinalan unha escasa presencia de peninsulares neste territorio que non superaría os 30.000 españois no ano 1910 (Lida, 2002, p. 616). No caso galego, Villaverde sinalou unha cifra próxima a 4.200 galegos e galegas entre 1878 e 1936 a partir da análise das tarxetas de identificación recollidas no Archivo General de la Nación (1999, p. 285).

Secasí, houbo casos de emigración cara México que representaron unha minoría pola súa importante posición económica, participando nas actividades produtivas e nos vínculos de poder do país (Rodríguez Galdo, Freire Esparís, Prada Castro, 1998, p. 51). Foron un colectivo importante no escalafón sociocultural daquel tempo, polo que non resultou unha mostra típica da migración galega. Pese a isto, tamén atopamos homes e mulleres de orixes humildes que apostaron por este destino. As listas de peninsulares están encabezadas por cántabros, vascos, casteláns, andaluces, cataláns e galegos (Pérez Acevedo, 2001, p. 140). A diferenza doutros emigrantes do Estado español, os galegos adoitaban emprestar os cartos da familia, veciñanza e coñecidos para pagar a pasaxe, evitando as problemáticas proposicións dos ganchos e das recrutas de pranteis. O esforzo económico era moi amplo, tal e como podemos imaxinar ao ver os altos prezos [táboa I] das pasaxes transoceánicas:

Táboa I

Anuncio da Compañía Holland American Line de Rotterdam. Comparativa de prezos entre Cuba e México.

\begin{tabular}{|l|l|l|}
\hline Clase & Destino & Prezo \\
\hline $3^{\mathrm{a}}$ & Cuba & 424 ptas \\
\hline $2^{\mathrm{a}}$ económica & México & 850 ptas \\
\hline $3^{\mathrm{a}}$ & Cuba & 482,75 ptas \\
\hline $2^{\mathrm{a}}$ económica & México* & 925 ptas \\
\hline \multicolumn{2}{|c|}{$\quad(*)$ Veracruz-Tampico } \\
\hline
\end{tabular}

Fonte: Galicia. Diario de Vigo, número 490, 20 de abril de 1924, p. 7.

A especulación do desprazamento arrastraba una enorme débeda que sería devolta por medio das remesas económicas xeradas nas Américas. En Cuba sempre había un tío, un veciño ou coñecido que podía axudar a introducir á emigrada nunha casa para labores domésticas ou para a sempre invisibilizada xestión do comercio (González Pagés, 2003). Pola contra, a aventura cara terras mexicanas resultaba máis azarosa primeiro polo prezo -como vimos na táboa- e logo debido ao escaso tecido migratorio galego establecido neste territorio. A fin de contas, para chegar a México había que facer parada na Habana. Que as invitaba a continuar a viaxe naval e por un prezo máis elevado e un maior risco? 
Se os factores de atracción dos países veciños resultaron determinantes, as noticias das mulleres arribadas a México tachaban este territorio dos destinos favorables para as galegas. Podémolo apreciar nun informe do Inspector General de Emigración do Ministerio de Trabajo y Previsión no ano 1921 no que se apuntan as restrinxidas condicións de permiso de entrada:

En cuanto a la entrada de extranjeros, las autoridades de migración en México tienen como norma general la de negársela a todos los que pretenden hacerlo en busca de trabajo o acomodo cuando no vayan a establecerse con recursos de importancia o cuente, por lo menos, ventajosos contratos. Quienes vayan a emplearse como domésticos o dependientes de comercio y, en general, en puestos que pueden ser desempeñados por naturales del país, serán repudiados, así como igualmente los menores de edad, siempre que se sospecha que van en busca de trabajo. (Informe 182, 1921, folio 13).

Esa referencia de traballos domésticos e dependentes de comercio englobaba labores desempeñadas por mulleres, deixando bastante claro que as autoridades mexicanas non permitirían o paso máis que a aquelas cun respaldo económico denostado. Unha medida proteccionista que fixo das aduanas e dos controis fronteirizos mexicanos lugares bastante arbitrarios. Non adoitaban estes informes diferenciar por xénero debido á maioría masculina destas remesas de migrantes, mais neste caso enfatízase a situación delas ao sinalar os distintos condicionantes que lles debían entregar ás autoridades para poder acceder ao territorio mexicano:

Por lo que se refiere a las mujeres que manifiesten van a México a casarse, se les exige que contraigan matrimonio abordo y antes de desembarcar en el país, presentando legalizado el permiso de sus padres, a las que por su minoría de edad les sea preciso, y un certificado de buena conducta expedido por las autoridades del lugar de procedencia. (Informe 182, 1921, folio 13).

Pechando este representativo informe, o inspector fai fincapé na problemática da prostitución. Sinálase que «todo esto a los efectos de evitar la entrada de contingentes de mujeres destinadas al comercio de la trata de blancas» (Informe 182, 1921, folio 13). Se a entrada ao territorio víase dificultada naquelas mulleres que quitasen un oficio a un natural do país, as mulleres galegas que lograban entrar sen unha protección socioeconómica podían ver atentada a súa liberdade, sinalando Lida o contraste entre o alto índice de prostitución dado entre as mulleres españolas alleas ás labores domésticas e a escasa participación das mulleres en tareas produtivas fóra do fogar (Lida, 1988, p. 334).

Vaiamos aos casos particulares. Acaso o colectivo galego foi unha figura visible neste tempo? No corazón da histórica rexión da Nueva Galicia chegou no ano 1910 Ramón C. Pérez. Nado no Cebreiro e emigrado á temperá idade de 15 anos fuxindo do 
recrutamento para a Guerra de Marrocos, marchou cara as Américas con tan só a carta dun galego que acollía aos galegos emigrados no seu abarrotes en Cedral, San Luis Potosí. Tras varios movementos arredor entre a fronteira estadounidense e mexicana, asentouse no Estado de Aguascalientes, casando cunha muller mexicana e permanecendo até a fin dos seus días nesta localización. Nunha entrevista realizada ao seu fillo Alfonso Pérez Romo, preguntándolle pola presencia de galegos neste territorio, asegura que o seu pai en moitas ocasións referenciou ser o único galego de Aguascalientes ${ }^{4}$. Si houbo varias familias asturianas e tamén vascas, pero de orixe galega dicía ser o único, reforzando a escasa visibilidade da migración feminina.

Malia isto, houbo casos de mulleres galegas afincadas en México noutras localizacións como no Estado de Puebla. Para o período suxeito a estudo, Elixio Villaverde sinalou catro casos: Adela Sobrado de Gavito, en 1909; Adelaida Sánchez de Díez, en 1903; Aurea Mier, tamén en 1903; e por último Consolación Rodríguez Ares, en 1922 (1999, pp: 288-309). No caso de Adela Sobrado, nada en Meira, declarou como profesión as labores do seu fogar, que sumado ao rexistro de casamento nos invita a pensar nunha boa posición económica propia das migracións á República. Do mesmo xeito aparece Adelaida Sánchez, casada cun inmigrante español acomodado do sector téxtil; mesmo sector que a familia de Aurea Mier e que reforza unha relevancia económica e social que permitiu a súa entrada no país. A única excepción foi a de Consolación Rodríguez, oriunda do Porriño, que marchou á emigración como muller solteira adicada a labores do fogar. Iso si, apareceu como a súa referencia en México o nome de Tomás Matanzo, polo que puido ter un auxilio para a súa inserción socioprofesional no Estado de Puebla (Villaverde, 1999, pp: 300-309).

O lugar con máis afluencia de migración galega na República foi Cidade de México. A formación do Centro Gallego de México levouse a cabo no Trívoli del Eliseo no ano 1908, nunha reunión «a la que asistieron un gran número de gallegos» (La Correspondencia Gallega, 1908, p. 2). Desta asociación de emigrados galegos recuperamos unha escolma fotográfica [fig. 3 e 4] na que se aprecian moitas das mulleres galegas emigradas a este territorio. Estas salientan por unha posición económica elevada cuxos maridos traballaban en sectores produtivos. Chégase a dicir que, nunha das súas reunións, Miguel Alessio Robles «[...] hace un canto de la mujer gallega que la sublimiza sacándola de la aldea donde trabaja, comparte con el hombre las fatigas del campo para elevarla con María Pita y Concepción Arenal hasta el Olimpo». (Eco de Galicia, 1926, p. 16).

4 Entrevista a Alfonso Pérez Romo, realizada en Aguascalientes (México). Disponible en: https://www. mazarelos.gal/2019/02/02/voceiros-migrados-ramon-carballo-perez-un-galego-na-nova galicia/ [Data de consulta: 20 de abril de 2020]. 

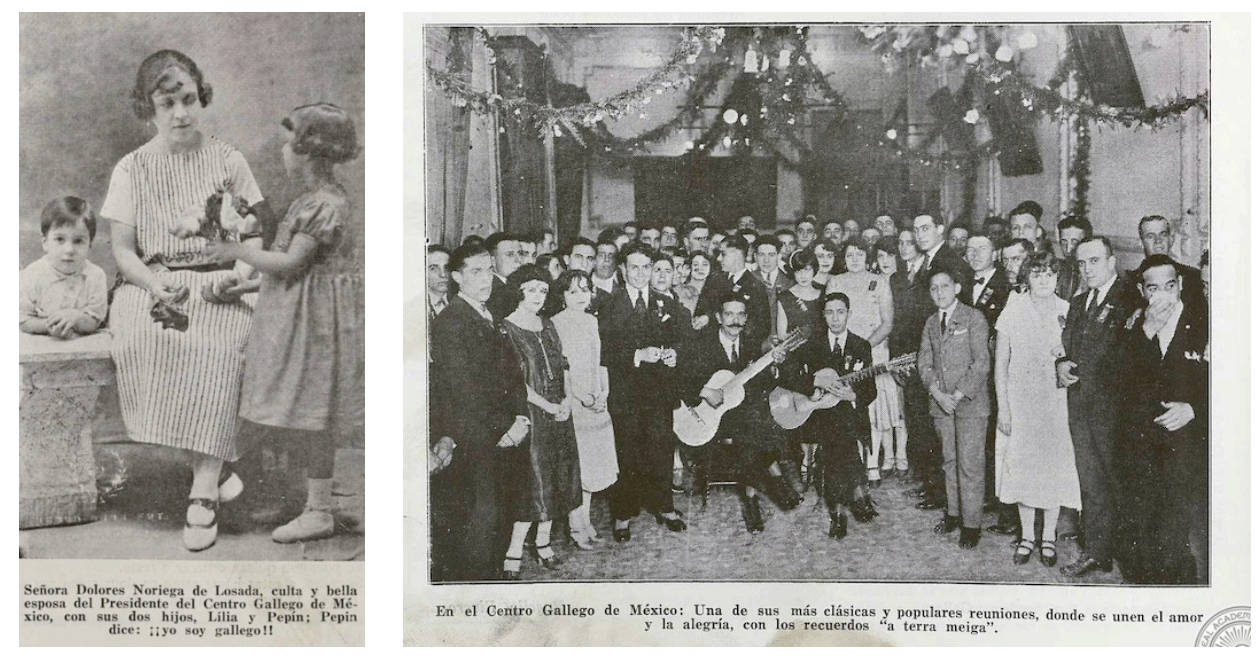

Fig. 3 e 4. Dolores Noriega de Losada, emigrada a México (esq.); reunión do Centro Galego (der.).

Fonte: Eco de Galicia, 305 (1926), pp: 15 e 16.

A Lei de Migración de 1926 esixiu un certo nivel de escolarización ou instrución, rematando cunha xa de por si escasa migración cara a México (Villaverde, 1999, p. 284). Un destino que non tiña suficientes vantaxes como para arriscarse, quedando as grandes vagas migratorias femininas na Habana dispostas á incorporación no eido doméstico ou nalgún pequeno negocio familiar. Porque se no resto de América eran os galegos os que levaban a cabo as tarefas máis forzosas, na República Mexicana había outro suxeito caracterizado para estes actos: os indios. Historicamente defenestrados, continuaban desempeñando as labores do fogar de xeito eficiente e con claras reminiscencias escravistas, polo que ese espazo adoitado pola muller galega quedaba copado.

\section{EPÍLOGO}

O camiño da emigración para as mulleres galegas resultou ser unha aventura perigosa. Máis que pola especulación e polas posibilidades laborais dos países de destino, a principal problemática foi o entramado que as rodeaba: a supremacía masculina e a cosificación da muller por medio da trata de brancas e da súa vulnerabilidade. Pese a isto, vimos como un importante número de mulleres galegas cruzaron o Atlántico, desenvolvendo unha labor que en moitos casos segue ficando intanxible na historiografía.

Se para eles o éxodo migratorio tiña como obxectivo acadar as cidades de Cíbola que as lendas prometían nas Américas, elas tiñan que analizar a situación máis sostible: o pequeno terruño que tiñan na Galiza ou a aventura na que poñían en risco as súas vidas dende o momento de partida até a dificultosa inserción sociolaboral. Concretando no caso 
mexicano, a migración galega foi tan reducida que se traduciu nunha casuística moi particular das mulleres. Se para os homes a entrada na República Mexicana era complicada, para elas ficou moi gravosa e chea de limitacións, ben sintetizado na prensa de época sinalando que «en México es barato hasta lo inverosímil el trabajo material [...] ¿A que ir allí mientras haya braceros que trabajan por tres y hasta dos reales de salario?» (Noticiero de Vigo, 1913, p. 1)

Foi por este motivo que a migración galega a México resultou tan particular e característica. A axenda da disciplina histórica ten unha tarefa pendente en canto a seguir descifrando a clave das dificultades atopadas na migración feminina e, especialmente, na particularidade do caso mexicano, onde si existiron casos de migración humilde alén dos enormes obstáculos. Por último, deixar formulada unha pregunta pertinente ao gallo dos apuntamentos presentados neste artigo: existiu unha convivencia na inserción laboral galega e india no ámbito doméstico en México? Un abano de cuestións que deben seguir sendo abordadas, abandonando unha tendencia á invisibilización da muller nos procesos migratorios dende xa vai demasiado tempo. 


\section{BIBLIOGRAFÍA}

Cagiao Vila, P. (1992): «La presencia gallega en otros lugares de América», en Cagiao Vila, P. (comp.) Galicia e América, cinco siglos de Historia, Galicia, Xunta de Galicia.

- 1999: Galegos en América e americanos en Galicia. Galicia, Xunta de Galicia.

- 2003: A muller galega na emigración a Cuba e Arxentina (1870-1930). Actas del congreso Internacional de Estudios Gallegos, Barcelona, Universitat de Barcelona.

- 2009: «Veinticinco años de investigación sobre emigración gallega a América», Minius, 17, pp. 145-166.

Campos Álvarez, J. R. (1993): «La emigración gallega a América (1880 - 1930). Integración y retorno». Minus, 2, pp. 133-148.

Castro Pérez, X. (1999): «A alimentación na viaxe dos emigrantes», en Cagiao Vila, P. (comp.): Galegos en América e americanos en Galicia, Galicia, Xunta de Galicia.

Fernández Prieto, L. (coord) (2000): Terra e progreso. Historia agraria da Galicia Contemporánea, Vigo, Xerais.

González Pagés, J. C. (2003): Emigración de mujeres gallegas a Cuba. Las Hijas de Galicia, Vigo, Concello de Vigo.

Hernández Borge, J. (2001): «Mujeres en la emigración exterior española a finales del siglo XIX», Xeográfica, 1, pp. 87-101.

— 2015: «Mujer gallega y emigración: estadísticas y bibliografía», en Hernández Borge, J. e Domínguez Lopo, D. (2015): Emigración y literatura: historias, experiencias y sentimientos. Actas del Coloquio Internacional, Santiago de Compostela. Universidade de Santiago de Compostela.

Iglesias López, M. R. «Con las raíces al aire. La experiencia de las emigrantes gallegas a través de nueve protagonistas», en Farías, R. (comp.) (2006): Buenos Aires Gallega. Inmigración, pasado y presente, Buenos Aires, Comisión para la preservación del Patrimonio histórico Cultural de la Ciudad de Buenos Aires.

Lida, C. E. (1988): «Los españoles en México. Del porfiriato a la Post-Revolución» en Españoles hacia América. La emigración en masa, Vigo, Unipro.

López Montero, C. (1983): La emigración española a Argentina (1890-1930), Madrid, Universidad Complutense de Madrid.

Moya, J. (2004): Primos y extranjeros. La inmigración española en Buenos Aires, Argentina, Emecé.

Naranjo Orovio, C. (1988): Del campo a la bodega: recuerdos de gallegos en Cuba, Galicia, Edicións do Castro.

Núñez Seixas, X. M. (2002): O inmigrante imaxinario: estereotipos, representacións e identidades dos galegos na Arxentina (1880-1940), Galicia: Universidade de Santiago de Compostela.

Ortiz Maddali, A. (2016): Left Behind: The Dying Principle of Family Reunification Under Immigration Law, vol. 50, 1. Dispoñible en:

http://repository.law.umich.edu/mjlr/vol50/iss1/3/). [Data de consulta: 2 de xuño de 2020]. 
Ortuño Martínez, B. (2010): El exilio y la emigración española de posguerra en Buenos Aires, Alacant, Universidad de Alicante.

Pérez Acevedo (2001): «La presencia española en México, 1821-1930. Un recuento historiográfico», Migraciones y exilios, 2, pp. 133-156.

Rial García, S. M. (2009): «Trabajo femenino y economía de subsistencia. El ejemplo de la Galicia moderna», Manuscrits, 27, pp. 77-99

Rodríguez Galdo, M. X., Freire Esparís, M. P. e Prada Castro, A. (coords.) (1998): Mulleres e emigración na Historia Contemporánea de Galicia, Galicia, Estudos migratorios.

Rodríguez Galdo, M. X. (1999): «Mujeres que emigran, mujeres que permanecen. Contribución a un estudio de la relación entre mujeres, economía campesina y emigración. Galicia, 1880-1930», en Arenal. Revista de Historia de las Mujeres, 6, pp. 265-294.

Samuelle Lamela, C. (2000) (coord.): La emigración gallega al río de la Plata. Galicia: Xunta de Galicia.

Sánchez Alonso, B. (1990): «Una nueva serie anual de la emigración española 1882 1930», Revista de Historia económica, 1, pp. 133-164.

Sánchez-Albornoz, N. (1995): Españoles hacia América. Una emigración en masa 18801930, Madrid, Alianza.

Sarmiento da Silva, É (2006): O outro Río. A emigración galega a Río de Janeiro, Santa Comba, Tresctres.

Vázquez González, A (1988): «La emigración gallega: Migrantes, Transporte y Remensas», en Sánchez Albornoz, N. (coord.) Españoles a América. La emigración en masa (1880-1930), Madrid, Universidad Complutense de Madrid.

- 2008: «Unha visión xeral da migración galega contemporánea a América e Europa» en Cid Fenández, XM et al (coords.): Migracións na Galicia contemporánea. Desafíos para a sociedade actual, Santiago de Compostela, Ed. Sotelo Blanco.

Villares Paz, R. (1982): La propiedad de la tierra en Galicia, 1500-1936, Madrid, Siglo XXI.

Villaverde, E. (1999): «Os galegos no estado e na cidade de Puebla á luz do Rexistro Nacional de Estranxeiros (1878-1936) », en Cagiao Vila, P. (comp.): Galegos en América e americanos en Galicia, Galicia, Xunta de Galicia.

\section{PRENSA}

Anónimo (16-10-1900): «La trata de blancas en los Estados Unidos». El Diario de Pontevedra. Número 4926, p. 1.

Anónimo (08-03-1921): «La emigración durante el último año». El Compostelano. Diario Independiente. Número 322, p. 3.

Anónimo (26-10-1903). El Correo de Galicia. Número 871, p. 2.

Anónimo (07-04-1927): «La Sociedad de naciones. La trata de blancas». El Compostelano. Diario Independiente. Número 2098, p. 1. 
Anónimo (23-07-1927): «La trata de blancas en la Argentina». El Compostelano. Diario Independiente. Número 2178, p. 2.

Anónimo (20-04-1924): «Precio del pasaje». El Correo de Galicia. Número 911, p. 7.

Redacción del Eco de Galicia (1926): «Desde México». El Eco de Galicia, núm. 305 (10).

Solá, J. (14-02-1913): «La situación de México y los españoles». El Noticiero de Vigo. Número 11.447, p. 1.

Vales Failde, J. (04-02-1901): «Las congregaciones religiosas y la emigración de las mujeres». El Áncora. Diario Católico de Pontevedra. Número 1048, p. 1.

\section{DOCUMENTACIÓN DE ARQUIVO}

1921. Informe Del Inspector General De Emigración. [Informe] Arquivo Provincial de Lugo, Folio 13. Lugo.

Ernesto Crespo (1926): “La Trata de Blancas". Boletín Oficial del Centro Gallego de Avellaneda. Número 236, p 16. Buenos Aires. Disponible en: http://biblioteca.galiciana.gal/gl/consulta/registro.do?id=10000274488 [Data de consulta: 2 de xuño de 2020]. 